\title{
REFORMASI PENDIDIKAN HUKUM DALAM PERSPEKTIF ABU AL-A'LA AL-MAUDUDI
}

\author{
Ibrahim \\ Universitas Islam Negeri Sultan Syarif Kasim Riau, Indonesia \\ Email:ibrahim@uin-suska.ac.id
}

\begin{abstract}
Looking at the various phenomena and human social status is not clear, especially in the state of Pakistan, the amount of depravity and nuances unsightly, and the vagueness of the law in the life of the application, push Abul A'la al-Maududi moved to reform legal education in Pakistan. Education reform law made Maududi can be seen in several steps: (1) master the Arabic language as a pre-condition for entering the legal academy; (2) study the Qur'an and hadith before beginning their education in the field of law; (3) The curriculum emphasizes the legal academy to three main subjects: the fundamentals of Islamic jurisprudence, the history of Islamic jurisprudence, and fiqh (neutral assessment on all the major schools of fiqh); and (4) together with the legal education curriculum reform, followed by upgrading the moral and character development of students.
\end{abstract}

Keywords: reformation, legal education, legal academy, Islamic jurisprudence

\section{A. Pendahuluan}

Pendidikan merupakan usaha yang dilakukan untuk meningkatkan mutu dan kekokohan suatu bangsa, di mana dalam realisasinya dibutuhkan berbagai planning yang matang demi mengangkat derajat dan martabat kehidupan manusia. Manusia sebagai makhluk yang berperadaban, sudah barang tentu mempunyai kecenderungan untuk merubah diri menuju suatu tuntutan idealitas yang kelak dapat mempertinggi kedudukannya di mata publik.

Melihat berbagai fenomena dan status sosial manusia yang tak jelas, khususnya di negara Pakisan, banyaknya kebejatan moral serta nuansa-nuansa yang tidak sedap dipandang mata, serta ketidakjelasan aplikasi hukum dalam kehidupan umat, mendorong Abul A'la al-Maududi tergerak untuk mereformasi pendidikan hukum di Pakistan. 


\section{B. Biografi Abu al-A'la al-Maududi}

Abu al-A'la al-Maududi dilahirkan pada tanggal 3 Rajab $1321 \mathrm{H}$ atau 25 September 1903 M di Aurangabad (sekarang disebut Andha Pradesh), Hyderabad, Deccan di India Selatan. ${ }^{1}$ Ayah Maududi, Ahmad Hasan yang dilahirkan pada tahun 1855 M di Delhi, berasal dari keluarga terhormat yang silsilah keturunannya dapat ditelusuri sampai kepada Nabi Muhammad saw. Keluarga Maududi telah mempunyai tradisi kepemimpinan spritual yang terkenal sejak lama karena sejumlah besar dari nenek moyangnya merupakan pemimpin tarekat yang terkemuka, di antaranya Khawajah Qutb al-Din Maududi (w. 527 H), seorang pendiri tarekat Chisty, aliran sufisme, yang ajarannya mencapai bagian benua Indo-Pakistan, melalui muridnya, Khawajah Maududdin Ajmeri. Pihak keluarga menyatakan berasal dari Maudud, perawi hadis Nabi yang konon tiba di India bersama Muhammad Ibn Qassim sejak akhir abad ke-13 H atau abad ke-15 M. Al-Maududi lahir dalam keluarga syarif (keluarga tokoh muslim India Utara) dari Delhi. Ayah Maulana Maududi adalah seorang seorang pengacara. $^{2}$

Keluarga Maududi pernah mengabdi di Moghul dekat dengan istana selama pemerintahan Bahadur Syah Zafar, penguasa terakhir dinasti itu. Keluarga Maududi kehilangan statusnya, setelah pemberontakan besar dan dinasti Moghul jatuh pada tahun $1858 \mathrm{M}$. Warisan pengabdian mereka kepada penguasa muslim menyebabkan mereka dapat terus merasa dekat dengan kejayaan sejarah muslim di India, karena itu mereka tidak akur dengan pemerintah Inggris. ${ }^{3}$

Keluarga Maududi meninggalkan Delhi, menetap di Deccan, dan mengabdi dari generasi demi generasi Nizam Hyderabad karena keluarga Maududi juga berasal dari India Utara membuat kedekatannya dengan warisan pemerintahan Islam di India,

\footnotetext{
${ }^{1}$ Khurshid Ahmad dan Zafar Ishaq Anshari, Islamic Perpectives: Studies in Honour of Mawlana Sayyid Abu al-A'la Maududi, (Leicerter: Islamic Foundation, 1980), hlm. 360

${ }^{2}$ Chaudhri 'Abdur Rahman 'Abd, Mufakkir-i Islam; Sayyid Abul A'laal-Maududi, (Lahore: Islamic Publications, 1971), hlm. 46-47.

${ }^{3}$ Maryam Jamilah, Biografi Abul A'la al-Maududi, terj. Dedi Djamaludin Malik, (Bandung: Risalah, 1984), hlm. 11.
} 
pretensi aristokratis, dan kebenciannya terhadap Inggris, memainkan peranan sentral dalam membentuk pandangan dunia Maududi di kemudian hari. ${ }^{4}$

Sayyid Ahmad Hasan, ayah Maududi, termasuk yang pertama masuk Sekolah Tinggi Anglo-Oriental Muslim yang didirikan Sayyid Ahmad Khan di Aligarh, dan ikut eksperimen dengan modernis Islam. Sayyid Ahmad Hasan keluar dari Aligarh untuk menyelesaikan studi dalam bidang hukum di Allahabad. Ketika menetap di Hyderabad, Sayyid Ahmad Hasan menjadi sufi (corak pemikirannya mengarah kepada tasawuf), kemudian pindah ke Delhi dan mengabdi di tempat suci Nizamuddin Awliya. ${ }^{5}$ Ahmad Hasan menyukai tasawuf, semangatnya menciptakan lingkungan yang sangat religius dan zuhud bagi pendidikan anaknya. Ahmad Hasan berupaya keras membesarkan anaknya dalam kultursyarif (kemuliaan), mendidik dengan pendidikan klasik. Anakanaknya diajarkan bahasa Arab, Persia dan Urdu di rumah, membaca teks sastra dan agama. Maududi sudah ahli dalam bahasa Arab pada usia muda, menguasai bahasa Arab dengan sangat baik, sehingga pada usia 14 tahun sudah dapat menerjemahkan al-Mi'rat al-Jadilah (wanita modern) karya Qasim Amin ke bahasa Urdu. ${ }^{6}$

Pada usia 11 (sebelas) tahun, Maududi masuk sekolah di Aurangabad, yang bernama Madrasah Fauqaniyah. ${ }^{7}$ Pendidikan awal Maududi diperoleh dari ayahnya sendiri di rumah, yang kemudian diteruskan kepada sekolah lanjutan ${ }^{8}$, yakni suatu sekolah yang menggabungkan pendidikan modern Barat dengan pendidikan Islam tradisional.Maududi terpaksa meninggalkan Hydrabad yang sedang belajar di Perguruan Tinggi Darul 'Ulum karena ayahnya sakit keras dan meninggal. ${ }^{9}$

Maududi mulai bekerja sebagai wartawan pada Akhbar Muslim. Sebagai wartawan, Maududi banyak menulis dan pandai mengeluarkan pikirannya sehingga berpengaruh besar pada pemikir muslim kontemporer, sejak dari Mindanao sampai

\footnotetext{
${ }^{4}$ Sayyid Vali Reza Nasr, Maududi dan Jama'at-i Islami; Asal-Usul, Teori dan Praktik Kebangkitan Islam, dalam Pioneers of Islamic Revival, terj. Ilyas Hasan, (Bandung: Mizan, 1995), hlm. 102 hlm. 27

${ }^{5}$ Sayyid Asad Gilana, Maududi; Thought and Movement, (Lahore: Islamic Publications, 1984),

${ }^{6}$ Sayyid Vali Reza Nasr, op.cit.,hlm. 103

${ }^{7}$ John L. Esposito, The Oxford Encyclopedia of The Modern Islamic World, Volume 3, (New York: Oxford University Press, 1995), hlm. 72

${ }^{8}$ Di madrasah inilah Abul A'la al-Maududi pertama kali mendapat pelajaran modern, khususnya sains. Amin Rais, "Kata Pengantar" dalam Khilafah wa al-Mulk, terj. Muhammad al-Baqir, (Bandung: Mizan, 1996), hlm. 7

${ }^{9}$ Ibid.,hlm. 103
} 
Maroko. Sejak Sayyid Qutb di Mesir, sampai aktivis kebangkitan Islam di Aljazair, Iran, Malaysia atau Sudan, berkembang di seputar mukaddimah Maududi Pengaruhnya yang paling kuat terasa di Asia Selatan yang membentuk pemikiran Maududi. ${ }^{10}$

Maududi berupaya untuk memenuhi minat intelektualnya pada persoalan politik, dan tidak tertarik pada persoalan agama.Pada waktu itu semangatnya adalah nasionalisme India.Antara tahun 1918 dan 1919, dia menulis beberapa esai yang memuji pemimpin Partai Kongres, khususnya Mahatma Gandi dan Madan Muhan Malaviya.Pada 1918, Maududi pergi ke Bijnur untuk bergabung dengan saudaranya, Abul Khair dan memulai karier di bidang jurnalis. Maududi berhadapan dengan berbagai arus intelektual dalam komunitas muslim dan mengenal tulisan para modernis serta kegiatan gerakan kemerdekaan. Pada tahun 1919, Maududi berpindah ke Jabalpur untuk bekerja pada mingguan Taj yang pro-Kongres, aktif dalam Gerakan Khilafat, dan dalam memobilisasi kaum muslim untuk mendukung Partai Kongres. Artikel-artikelnya yang bersemangat akhirnya membuat mingguan ini ditutup oleh pihak berwenang karena mereka khawatir akan mendapat gebrakan yang menjatuhkan martabat mereka di kemudian hari. ${ }^{11}$

Kembali ke Delhi, Maududi berkenalan dengan para aktivis penting Gerakan Khilafat, seperti Muhammad 'Ali dan sempat bekerja sama untuk waktu yang singkat. Maududi melanjutkan ketertarikannya dengan gerakan kemerdekaan, kali ini dari sudut pandang seorang muslim yang makin mengental. Misalnya, sempat bergabung sebentar dengan gerakan protes Tahrik-i Hijrat yang mendorong umat Islam untuk hijrah dari India yang diduduki oleh Inggris (dar al-harb, daerah perang) ke Afghanistan yang diperintah oleh seorang muslim (Dar al-Islam, negeri Islam). ${ }^{12}$

Pada 1921, Maududi berkenalan dengan para pemimpin senior Jam'iyatul 'Ulama'-i Hind, yaitu Maulana Mufti Kifayatullah dan Ahmad Sa'id. Ulama besar ini terkesan pada Maududi dan menawarinya untuk menjadi editor surat kabar resmi Jam'iyat Muslim, yaitu al-Jam'iyyat. Maududi tetap di Jam'iyat sampai 1924. Di sana, dia menjadi jauh lebih memahami kesadaran politik muslim dan menjadi lebih aktif

\footnotetext{
${ }^{10}$ Sayyid Vali Reza Nasr, op.cit.,hlm. 101. John L. Esposito menguraikan tentang dampak pemikiran Maududi pada gerakan Islam di dunia Arab, Afghanistan, Iran dan Malaysia. John L. Esposito, The IslamicThreat; Myth or Reality, (Bandung: Mizan, 1994), hlm. 154-155

${ }^{11}$ John L. Esposito, op. cit., hlm. 73

${ }^{12}$ Ibid.
} 
terlibat dalam urusan keagamaan. Dia mulai menulis tentang keprihatinan muslim di India. Kesulitan Turki dalam menghadapi imperialisme Eropa, dan kejayaan penguasa muslim di India. Meskipun nada tulisannya komunalis dan politis, kebangkitan Islam belum menjadi fokus sentral dalam tulisannya. ${ }^{13}$

Kondisi ini merupakan periode belajar dan pertumbuhan intelektual Maududi dengan mempelajari bahasa Inggris dan berkenalan dengan karya-karya Barat.Hubungan dengan Jam 'iyat mendorongnya untuk memperoleh pendidikan agama formal.Maududi mempelajari bahasa Arab dan memulai dars-i nizhami (silabus pendidikan ulama di India) pertama kali dengan 'Abdussalam Niyazi dan kemudian di Madrasah Fatihpuri Delhi.Pada 1926, Maududi menerima ijazah pendidikan agama dan menjadi ulama Deobandi.Namun, Maududi tidak pernah mengakui status sebagai seorang ulama, dan pendidikannya dalam tradisi Deobandi baru diketahui setelah dia wafat tahun $1979 .^{14}$

Pada tahun 1940, Maududi mengembangkan pikiran untuk mendirikan gerakan yang lebih komprehensif dengan mendirikan organisasi Jama'at-i Islami dan menjadi ketua hingga tahun 1972. ${ }^{15}$ Pada waktu dua negara anak benua India didirikan yaitu Pakistan dan India tahun 1947, Jama'at terbagi menjadi Jam'at-i Islam India dan Jamaat-i Islam Pakistan.Maududi memusatkan perhatian kepada mendirikan suatu negara Islam dan masyarakat Islam yang sebenarnya di Pakistan sejak Agustus 1947. ${ }^{16}$ Maududi banyak menulis untuk menerangkan aspek-aspek yang berbeda dari jalan hidup Islam, terutama aspek sosio-politik.Perhatiannya untuk menerapkan kehidupan Islam membawa Maududi mengkritik dan melawan kebijakan yang dilakukan oleh pemerintah Pakistan, dan menuduh penguasa gagal untuk mengubah Pakistan menjadi negara Islam yang sebenarnya. ${ }^{17}$

Ide-ide dan serangan Maududi yang gencar terhadap penguasa, mengakibatkan Maududi sering dipenjarakan dalam waktu lama.Perjuangan dan pengorbanan Maududi menunjukkan kesan kepada orang-orang, termasuk orang yang mengkritik dan melawannya, tentang kekuatan, kemauan kerasnya dan sifat luar biasa yang ada

\footnotetext{
${ }^{13}$ Ibid.

${ }^{14}$ Ibid., hlm. 74

${ }^{15}$ Mukti Ali, op. cit., hlm. 241

${ }^{16}$ Ibid.

${ }^{17}$ Ibid.
} 
padanya. Kekerasan tekad dan hati Maududi, menyebabkan ia hampir dihukum mati. Namun karena banyak dukungan yang membela dan mengikuti perjuangannya, Maududi hanya dihukum dengan hukuman seumur hidup.

Maududi menjadi Jurnalis setelah pendidikan formalnya terputus sebagai mata pencahariannya. Pada tahun 1918, menyumbangkan tulisan-tulisan kepada surat kabar yang berbahasa Urdu setempat dan dalam usia tujuh belas tahun (1920) diangkat sebagai editor harian Taj di Jabalpur (satu kota di propinsi Madhya Pradesh, India). Akhir tahun 1920, Maududi datang ke Delhi dan memimpin edisi surat kabar Muslim (1921-1923), kemudian menjadi redaktur surat kabar al-Jam'iyat (1925-1928). ${ }^{18}$

Pada tahun (1920-1928), Maududi menerjemahkan empat buah buku, satu dari bahasa Arab dan tiga lainnya dari bahasa Inggris. Di samping itu, pada tahun 1926, menulis buku yang berjudul al-Jihad fi al-Islam. Buku ini membahas secara cermat tentang hukum Islam dalam keadaan perang dan damai. Karya Maududi ini telah mendapat perhatian besar dan sambutan yang baik dari dunia akademis, terutama dari seorang pujangga-filosuf kenamaan, Muhammad Iqbal dan seorang pemimpin terkemuka dari gerakan khilafah dan kemerdekaan, Maulana Muhammad Ali Jawhar. ${ }^{19}$

Maududi pindah ke Hyderabad pada tahun 1928 untuk menekuni penelitian dan penulisan. Pada tahun 1932, sekali lagi Maududi mendapat perhatian besar dari kalangan intelektual karena bukunya yang berjudul Towards Understanding Islam. Buku ini kemudian diterjemahkan ke dalam berbagai bahasa di dunia. Pada tahun 1933, dia menerbitkan surat kabar bulanan Tarjuman al-Qur'an, yang sejak itu sampai saat ini tetap menjadi wahana utama bagi penyebaran gagasan-gagasannya. Melalui media itu, Maududi memusatkan perhatiannya untuk memaparkan ide-ide, nilai-nilai dan prinsipprinsip dasar Islam. Maududi sangat memperhatikan persoalan yang timbul sebagai akibat dari konflik antara pandangan dunia Islam dan Barat kontemporer, berusaha mendiskusikan masalah-masalah pokok di zaman modern ini, dan mencoba untuk mengajukan pemecahan secara islami. Maududi mengembangkan sebuah metodologi baru untuk mengkaji berbagai masalah dalam konteks pengalaman Barat dan dunia

\footnotetext{
${ }^{18}$ Khurshid Ahmad \& Zafar Ishaq Ansari, Mawlana Sayyid Abul A'la Mawdudi: an Introduction to His Vision of Islam and Islamic Law Revival, dalam Khurshid Ahmad \& Zafar Ishaq Ansari (Ed.), "Islamic Perspectives: Studies in Honour of Mawlana Sayyid Abul A'la al-Mawdudi", (Leicester: Islamic Foundation, 1980), Cet. Ke-2, hlm. 361

${ }^{19}$ Ibid.
} 
Islam dengan menilai dari menyesuaikannya dengan al-Qur'an dan al-sunnah. Semua karya Maududi memperlihatkan kedalaman ilmunya tentang al-Qur'an dan al-sunnah. ${ }^{20}$

Pada bulan Januari 1938, Maududi datang ke Punjab atas ajakan Muhammad Iqbal untuk kerjasama dalam rangka pembaharuan hukum Islam dengan mendirikan sebuah pusat akademis dan penelitian, Dar al-Islam, yang direncanakan untuk melatih para sarjana yang kompeten dalam masalah keislaman agar mereka menghasilkan karya-karya yang bermutu tinggi, dan terutama untuk membangun kembali hukum Islam. Sayang sekali, Iqbal keburu meninggal dunia beberapa bulan kemudian. Oleh karena itu, Maududi terpaksa meninggalkan Punjab dan berpindah ke Lahore di mana ia menjadi staf pengajar pada Fakultas Ushuluddin di Islamiah College selama setahun tanpa bayaran. ${ }^{21}$

Pada tahun 1948, Maududi pernah menyampaikan lima buah ceramah lewat radio Pakistan, yang ditujukan kepada masyarakat Islam bukan hanya di Pakistan melainklan juga di seluruh dunia. Ceramah tersebut mencakupi lima bidang pokok dalam kehidupan umat Islam, yaitu bidang moral, politik, sosial, ekonomi dan spritual. Kelima ceramah kemudian diterbitkan oleh Islamic Research Academy dalam bentuk buku yang diberi judul Islamic Way of Life. ${ }^{22}$

Antara tahun 1939-1958, Maududi menyempurnakan berbagai kuliah dan tulisannya yang kemudian dihimpun dalam satu buku yang berjudul Islamic Law and Constitution. Pada tahun 1959-1960, dia banyak berkunjung ke Timur Tengah seperti Saudi Arabia, Sryia, Jordania, dan Mesir. Dia berziarah ke tempat-tempat bersejarah yang disebut dalam al-Qur'an dan Injil dalam usahanya untuk menyiapkan tafsir alQur'an yang berjudul Tafhim al-Qur'an yang dapat diselesaikan pada bulan Juni 1972 dan mendapat sambutan yang luas di seluruh kawasan dunia Islam. Tafsir yang ditulis Maududi ini merupakan yang terbesar yang dipersiapkannya selama tiga puluh tahun. Ciri-ciri utama tafsir ini adalah menyajikan arti dan risalah al-Qur'an sebagai bahasa dan gaya tarik yang menyerap ke dalam hati dan pikiran setiap insan dewasa ini. Maududi menunjukkan relevansi al-Qur'an dengan berbagai problema sehari-hari, baik secara

\footnotetext{
${ }^{20}$ Ibid., hlm. 362

${ }^{21}$ Maryam Jamilah, Biografi Abul A'la Maududi, terjemahan Dedy Djamaluddin Malik dari buku aslinya "Who is Maudoodi", (Bandung: Risalah, 1984), hlm. 5

${ }^{22}$ Ibid., hln. 16
} 
individual maupun secara kolektif atau sosial. Dia berusaha menjelaskan ayat-ayat Allah dalam konteks pesan yang menyeluruh. ${ }^{23}$

Selama perjalanannya pada tahun 1956-1974, Maududi sempat memberikan kuliah di berbagai kota dunia, yaitu: Kairo, Damaskus, Amman, Makkah, Madinah, Jeddah, Kuwait, Rabat, Istanbul, London, New York, dan menjadi tamu di berbagai pusat internasional. Pada tahun 1961, atas permintaan Raja Ibn Saud dari Saudi Arabia, Maulana Maududi mempersiapkan rancangan terperinci tentang pembangunan universitas di Madinah yang nantinya diharapkan mampu melahirkan kaum intelektual muslim. Di samping itu, dia juga menjadi anggota pendiri Rabithah al-'Alam al-Islami yang berpusat di Makkah dan merangkap sebagai anggota Akademi Penelitian Hukum di Madinah. ${ }^{24}$

Kecenderungan Maududi pada soal-soal politik, sudah terlihat ketika antara tahun 1920-1928, dia turut aktif dalam gerakan khilafah dan gerakan hijrah serta berbagai gerakan kemerdekaan meskipun kemudian dia mengundurkan diri dari organisasi-organisasi itu karena perbedaan strategi. Pada tahun 1937, dia mulai betulbetul memperhatikan soal-soal politik. Mulai tahun itu dia terlibat lebih mendalam dan langsung. Ketika itu, India telah mendekati titik-titik kemerdekaan setelah kira-kira 150 tahun dikuasai oleh kerajaan Inggris. Pada saat itu, pengaturan konstitusional masa depan India yang merdeka telah menjadi perdebatan berbagai partai orang India yang menentang Inggris. Dalam keadaan seperti itu, Maududi menyadari akan adanya suatu bahaya besar yang akan mengancam eksistensi kaum muslimin. Maududi sangat khawatir kalau tatanan politik yang dibangun akan menghilangkan identitas muslim, kebudayaan dan agamanya, dan kaum muslimin akan tenggelam dalam peradaban mayoritas Hindu. Pada tahun 1937-1941, dia berusaha memperingatkan kaum muslimin dari bahaya besar yang bakal terjadi kalau orang-orang muslim tidak berjuang demi Islam. Untuk itu, dia menerbitkan tulisan-tulisan tentang soal-soal politik dalam Tarjuman al-Qur'an, yang kemudian dicetak dalam bentuk buku dalam tiga jilid yang

\footnotetext{
${ }^{23}$ Ibid., hlm. 364

${ }^{24}$ Ibid.
} 
berjudul Musulmanon awr Maujudah Siyasi Kashmakash, dan yang berjudul Masalah-I Qawmiyat. $^{25}$

Kekhawatiran Maududi itu berpangkal pada sikap Kongres Nasional yang menegaskan bahwa semua orang India adalah satu bangsa, dan pemerintahan India pasca merdeka harus demokratis dan sekuler. Hal itu sangat bertentangan dengan pandangan yang diyakini Maududi. Menurutnya, umat Islam India dan umat-umat lain, terutama umat Hindu, bukanlah bangsa yang sama. Dengan tegas, dia menyatakan bahwa kaum muslimin memiliki identitas dan kebangsaan sendiri, yaitu Islam. Lebih jauh lagi, dia mengungkapkan bahwa kaum muslimin bersatu bukan karena ikatan ras, geografis, bahasa, kepentingan bersama, ekonomi, atau budaya, melainkan karena komitmen mereka untuk mengikuti kehendak Allah swt. dalam kehidupan mereka. ${ }^{26}$

Maududi menolak keras faham-faham nasionalisme, demokrasi dan sekuler yang dinyatakannya sebagai faham yang bertentangan dengan agama. Dia menyerukan kaum muslimin untuk tidak berjuang atas faham-faham tersebut karena akan merugikan kelompok muslim yang minoritas. Dia mendesak kaum muslimin untuk tidak ikut serta dalam perjuanaan kemerdekaan yang dipimpin Kongres Nasional India dan para pendukung nasionalisme. ${ }^{27}$

Terhadap faham demokrasi, dia melontarkan kecaman keras karena menurutnya, faham itu akan hanya menjadi tirani mayoritas, sedangkan kaum muslimin jelas merupakan kaum minoritas di India. Jika kaum muslimin menerima faham itu, mereka akan kehilangan identitas Islam mereka dan hancur. Demikian pula dengan sekularisme, Maududi mengkritik faham itu karena suatu tatanan sosial tanpa agama tidak dapat diterima dan jelas bertentangan dengan Islam. Lebih lanjut, dia menegaskan bahwa suatu sistem pemerintahan sekuler, secara teoretis, akan mengambil sikap netral terhadap semua kelompok agama, dan memperlakukan mereka secara sama. Akan tetapi, sikap netral tersebut dalam prakteknya tidak akan pernah terwujud di India karena pemerintah hanya akan bersikap sekuler terhadap kelompok-kelompok agama

\footnotetext{
${ }^{25}$ Charles J. Adams, Maududi dan Negara Islam, dalam John L. Esposito (Ed.), Dinamika Kebangunan Islam, Terjemahan Bakri Siregar dari buku aslinya "Voices of Resurqen Islam", (Jakarta: Rajawali, 1987), Cet. Ke-1, hlm. 115

${ }^{26}$ Ibid.

${ }^{27}$ Ibid., hlm. 116
} 
minoritas, yaitu tidak membantu ataupun menekan mereka, dan sebaliknya, jika perlu akan mendukung agama mayoritas. ${ }^{28}$

Karena kegiatan politik muslim di India tidak memenuhi kebutuhan kaum muslimin, Maududi memulai usaha pembaharuan Islam dengan mendirikan suatu organisasi, yaitu Jama'at-i-Islami di Lahore pada bulan Agustus 1941, dan dia terpilih sebagai amir (pemimpin) sampai tahun 1972, pada saat dia mengundurkan diri karena alasan kesehatan. Organisasi itu bertujuan agar "seluruh sistem kehidupan manusia dalam segala bagiannya harus didirikan atas pengabdian kepada Allah swt. dan bimbingan para Rasul" ${ }^{29}$ Jama'at-i-islami anak benua India. $^{30}$

Pada tahun 1947, ketika anak benua ini memperoleh kemerdekaan dalam bentuk dua negara terpisah -Pakistan dan India- Jama'at-i-Islami juga ikut terbagi dua: Jama'at-i-Islami Pakistan dan Jama'at-I Islami India. Pada awalnya, Maududi termasuk orang yang menentang pembagian India menjadi dua negara yang terpisah karena dia yakin bahwa para pemimpin Liga Muslim tidak mungkin mampu menciptakan negara yang didambakannya. Akan tetapi, setelah melihat kenyataan bahwa kaum muslimin dan Hindu tidak bisa hidup ,bersama di satu negara India, akhirnya dia mendukung gerakan pembagian India tersebut. Oleh sebab itu, sejak anak benua itu merdeka, dia berhijrah ke Pakistan dan memusatkan usahanya untuk membangun negara dan masyarakat Islam. Secara konsisten, dia banyak menulis untuk menjelaskan berbagai aspek cara hidup Islam, terutama aspek sosial-politiknya. Keperihatinannya terhadap implementasi cara hidup Islam telah menyebabkannya mengecam dan menentang kebijaksanaan yang dijalankan oleh pemerintah sejak Pakistan berdiri karena pemerintah gagal mengubah negeri itu menjadi negara Islam. Sebagaimana dikatakan oleh Maryam Jamilah bahwa dengan semangat yang tak kenal lelah, Maududi telah mengelilingi seluruh negeri Pakistan dengan melakukan berbagai pidato untuk menggerakkan dukungan rakyat. ${ }^{31}$ Mobilisasi Maududi ini bertujuan untuk menekan sedapat mungkin Majelis Konstituante Nasional (didirikan pada bulan Juli 1946) yang ditugaskan untuk merancang suatu konstitusi yang berdasarkan atas prinsip-prinsip

\footnotetext{
${ }^{28}$ Ibid., hlm. 117

${ }^{29}$ Ibid., hlm. 119

${ }^{30}$ Ibid.

${ }^{31}$ Maryam Jamilah, op.cit.,hlm. 16
} 
Islam agar memuatkan tuntutan dan aspirasi rakyat muslimin yang dirumuskan dalam empat butir sebagai berikut:

(1) bahwa kedaulatan negara Pakistan berada di tangan Tuhan yang Mahakuasa, dan bahwa pemerintahan Pakistan hanya akan menjadi agen untuk melaksanakan kehendak Yang Berdaulat

(2) bahwa Syari'ah Islam harus membentuk norma dasar oleh perundang-undangan yang berada di bawahnya

(3) bahwa semua perundang-undangan yang ada atau yang akan dibentuk, baik dalam materi maupun semangatnya harus sejalan dan bersumber syari'ah sebagai sumber dari segala sumber hukum

(4) bahwa kekuasaan pemerintah Pakistan harus bersumber dari, dibatasi oleh, dan dilaksanakan hanya di dalam batas-batas syari'ah. ${ }^{32}$

Karena penguasa tidak menerima tuntutan rakyat yang disebarluaskan Maududi itu, maka dia beserta beberapa sahabatnya ditangkap dan dijebloskan di penjara sejak tanggal 4 Oktober 1948 sampai 28 Mei 1950 berdasarkan undang-undang keselamatan umum. Larangan juga dikenakan terhadap media-massa, surat kabar dan jurnal yang aktif memperjuangkan tuntutan tersebut. ${ }^{33}$

Karena desakan rakyat yang tidak bisa dibendung, akhirnya Dewan Konstituante Pakistan terpaksa menyetujui Resolusi Objektif (7 Maret 1949) yang memuat semua tuntutan Maududi. Namun, satu setengah tahun kemudian, yaitu pada bulan September 1950, pemerintah mengeluarkan Laporan Komite Prinsip Dasar yang berisi pernyataan yang sama sekali berlawanan dengan Resolusi Objektif tersebut. Kali ini, untuk menekan pemerintah, maududi mengelilingi seluruh negeri Pakistan Barat, dan pada waktu yang sama Jami'at al-Ulama melakukan hal yang sama pula di Pakistan Timur untuk menggerakkan masyarakat Islam untuk melawan laporan itu. Orang-orang Islam yang pro negara Islam dalam waktu yang singkat telah bangkit untuk menentang kebijaksanaan pemerintah. Akan tetapi, pemerintah telah menanggapi oposisi rakyat dengan melakukan kampanye pemerasan, pemaksaan, penculikan dan sebagainya terhadap mereka yang menentang kebijaksanaan pemerintah itu. Salah satu alasan

\footnotetext{
${ }^{32}$ Abul A'la al-Maududi, The Islamic Law and Constitution, (Lahore: Islamic Publications Ltd, 1977), Cet. Ke-6, hlm. 48

${ }^{33}$ Ibid.,hlm. 48-49
} 
pemerintah untuk menolak gagasan negara Islam adalah karena tidak adanya kesepakatan di antara kelompok kelompok Islam yang saling mempertentangkan pandangan mazhab yang mereka anut, sehingga menurut pemerintah, tidak mungkin diperoleh satu versi Konstitusi Islam dalam keadaan seperti itu. ${ }^{34}$

Alasan pemerintah itu tidak terbukti kebenarannya, karena pada tanggal 21-24 Januari 1951 di Karachi, tiga puluh satu ulama yang mewakili semua mazhab Islam di Pakistan atas bujukan Maududi telah berhasil merumuskan secara konsensus 22 Prinsip Negara Islam. ${ }^{35}$ Peristiwa yang luar biasa itu telah menggugurkan kebenaran pernyataan pemerintah di atas.

Meskipun keterangan antara rakyat dan pemerintah telah reda setelah keberhasilan para ulama dalam merumuskan prinsip-prinsip negara Islam tersebut, kecurigaan rakyat terhadap pemerintah mulai muncul sesudah delapan belas bulan karena belum ada berita tentang keputusan pemerintah mengenai penerapan konstitusi Islam itu. Pihak penguasa selalu berusaha untuk menunda-nunda impelentasi Konstitusi itu. Pada bulan Mei 1952, Maududi mengecam keras dan mendesak pemerintah agar masalah Konstitusi itu harus diselesaikan sebelum akhir tahun 1952, dan harus mengandung pokok-pokok ini:

(1) bahwa Syari'ah Islam harus membentuk hukum tanah (agraria)

(2) bahwa tidak boleh ada perundang-undangan yang mengatasi ataupun bertentangan dengan pasal mana pun yang tercantum di dalam prinsip-prinsip Syari'ah

(3) bahwa semua peraturan hukum yang bertentangan dengan prinsip-prinsip Syari'ah harus dinyatakan batal

(4) bahwa negara harus membasmi kejahatan-kejahatan yang ingin dibasmi oleh Islam, dan menjunjung tinggi serta mempertahankan kebajikan-kebajikan yang menurut Islam perlu dijunjung tinggi dan ditegakkan

(5) bahwa tidak ada satu pun hak-hak kewarganegaraan rakyat - keaman hidup dan kekayaan, dan kebebasan berserikat dan berkumpul - yang boleh dicabut atau dihalang-halangi kecuali jika suatu tindak pidana telah menjadi dan dibuktikan

\footnotetext{
${ }^{34}$ Ibid.,hlm. 49-50

${ }^{35}$ Ibid.,hlm. 50
} 
dalam suatu pengadilan terbuka sesudah memberi peluang untuk mengajukan pembelaan

(6) bahwa rakyat berhak menuntut anggota-anggota legislatif maupun mesin eksekutif negara yang melanggar hukum

(7) bahwa lembaga kehakiman harus kebal terhadap semua campur tangan eksekutif]

(8) bahwa negara harus diberi kewajjiban untuk mengawasi dan menjaga agar tidak ada satu pun warga negara yang tidak memperoleh atau menikmati dan memenuhi kebutuhan pokoknya seperti sandang, pangan, papan, kesehatan dan pendidikan. ${ }^{36}$

Berdasarkan tuntutan rakyat yang dipelopori Maududi ini, penguasa hanya bisa menerima sebagian dan memasukkannya ke dalam Laporan Komite Prinsip-Prinsip Dasar pada bulan Desember 1952. Kemudian pada bulan Januari 1953, para wakil dari ulama dari berbagai mazhab mengadakan suatu pertemuan di Karachi untuk memutuskan penerimaan Laporan tersebut dengan beberapa usulan perbaikan. Meskipun tuntutan kelompok muslim ini sempat ditampung dalam konstitusi. Sementara pada kabinet Nazimuddin, Konstitusi tersebut tidak bertahan lama karena kabinet itu dibubarkan dan diganti dengan kabinet Muhammad Ali Bogra yang sangat represif terhadap para pembela Islam. Muhammad Ali Bogra sendiri berjanji akan memberlakukan konstitusi itu pada tahun 1954 setelah diperbaiki kembali oleh Dewan Konstituante. Akan tetapi, konstitusi itupun gagal diterapkan karena Dewan Konstituante itu dibubarkan. Akhirnya, kelompok westernis berhasil membentuk konstitusi yang mereka inginkan. ${ }^{37}$

Pada tanggal 28 Maret 1953, sekali lagi, Maududi ditangkap dan dipenjarakan sehubungan dengan tulisannya yang berjudul The Qadiani Problems. Tulisan Maududi ini bertujuan untuk mendukung tuntutan rakyat yang menginginkan agar orang-orang Qadiani harus diperlakukan sebagai kelompok minoritas, alias non muslim dalam konstitusi Pakistan, tetapi pemerintah tidak menerima tuntutan tersebut dan bahkan Maududi dituduh oleh pemerintah sebagai penghasut. Berkaitan dengan peristiwa itu, Maududi oleh pengadilan darurat dijatuhkan hukuman mati di tiang gantungan. Ketika

\footnotetext{
${ }^{36}$ Ibid.,hlm. 50-51

${ }^{37}$ Ibid.,hlm. 50-51
} 
mendengar vonis pengadilan itu, Maududi sedikit pun tidak bergetar, bahkan sebaliknya dia berkata: "Jika ajal saya telah tiba, tak seorang pun dapat mencegah saya darinya; dan jika ajal belum tiba, mereka tidak dapat menggiring saya ke tiang gantungan meskipun mereka menggantung diri mereka sendiri untuk menggantung saya". ${ }^{38}$

Meskipun Maududi sering dipenjara, perjuangannya tidak pernah berhenti demi tercapainya cita-citanya, yaitu tegaknya tatanan Islam di negara Pakistan. Kegigihan Maududi itu diungkapkan oleh Erwin I.J. Rosenthal sebagai berikut:

"Saya hampir cenderung berpendapat bahwa hanya Sayyid Abul A'la Maududi dan Jama'at-I Islami-nya yang mempunyai tujuan yang jelas dan berusaha untuk itu dengan maksud dan kebulatan tekad yang tunggal, mempergunakan cara-cara yang ditiru dari filsafat-filsafat dan pergerakan-pergerakan politik yang berpandangan menyeluruh. Lebih dari itu, Maududi dan para pengikutnya telah mempunyai konsep tentang negara Pakistan yang mereka inginkan, yaitu suatu tatanan Islam." ${ }^{39}$

Sampai akhir hidupnya, Maududi selalu aktif dalam berbagai kegiatan untuk mewujudkan negara Pakistan yang berdasarkan al-Qur'an dan al-sunnah, sebagaimana diketahui, perjuangan Maududi itu berjalan selama enam puluh tahun ketika ajalnya tiba pada tangga 23 September 1979, yaitu setelah dirawat beberapa hari di sebuah rumah sakit di kota New York. ${ }^{40}$

Mengenai karya-karya Abul A'la al-Maududi, sepanjang hayatnya, lebih dari 138 buah karya termasuk rencana ilmiah, risalah dan kitabnya. Karya-karya tersebut sebagai berikut:

1. Abu Hanifah and Abu Yusuf, in A History of Muslim Philosophy

2. Adabiyat-i Mawdudi (Literary Writings of Mawdudi)

3. Bana'o awr Bigar? (Nations Rise and Fall-Why?)

4. Come Let Us Change This World; Selections from the Writings of Mawlana Mawdudi)

5. Correspondence between Maulana Mawdudi and Maryam Jameelah

6. Dakan kl Siyast Tarikh (The Political History of (Hyderabad)

\footnotetext{
${ }^{38}$ Khurshid Ahmad \& Ishaq Ansari, op.cit.,hlm. 363

${ }^{39}$ Erwin I. J. Rosenthal, Islam in The Modern National State, (Cambridge: University Press, 1965), hlm. 247

${ }^{40}$ Munawir Sadzali, Islam dan Tata Negara: Ajaran, Sejarah dan Pemikiran, (Jakarta: UI-Press, 1990), hlm. 158
} 
7. Dasturi Sifarishat par Tanqid; Islami awr Jamhuri Nuqta-i Nazar se (A Critique of the Constitusional Proposals from the Islamic and Democratic Viewpoints)

8. Dasturi Tajawiz (Constitusional Proposals)

9. Dasturi Tajawiz par Tanqid-o-Tabsirah (Criticism of The Constitusional Proposals)

10. Da'wat-i Islami awr us ke Mujalabat (The Islamic Movement and its Requirements)

11. Daiwat-i Islami kiya hay?(What is the Islamic Movement?)

12. Da'wat-i Islami men Khawatin ka Hissah (Women's Role in the Promotion of the Islamic Movement)

13. Da'wat-i Islami, us ke Usul, Tariq-i kar awr Muqtadiyat (The Islamic Movement, its principles, methodology and requirements)

14. Dawr-i Naw ka Chailanj awr Nawjawan

15. Din-i Haqq (The Religion of Truth)

16. Economic and Political Teachings of the Qur'an: in A History of Muslim Philosophy)

17. Ek Nihayat aham Istifta' (A Highly Important Query)

18. Fadail-i-Qur'an (Excellence of the Qur'an)

19. Fasadat-i Panjab kl Tahqiqatl 'Adalat ke samne Sayyid Abul Abul A'la alMaududila Mawdudi ka Bayan (Statement of Syed Abul A'la al-Mawdudi before the Punjab Disturbances Court of Enquiry)

20. Ghilaf-i Ka'bah, us kl Shar'i Haythiyat, us kl Tarikh (The Cover of the Ka'bah, its legal position, its history)

21. Hadith awr Qur'an (Hadith and Qur'an)

22. Hamare Dakhilt wa Kharijl Masail (Our Internal and External Problems)

23. Haqiqat-i Hajj (Pilgrimage in Islam)

24. Haqiqat-i Iman (Included in the Essence of Iman)

25. Haqiqat-i Islam (Included in the Essence of Islam)

26. Haqiqat-i Jihad (War in the Way of Islam)

27. Haqiqat-i Sawm-o Salat (Worship in Islam)

28. Haqiqat-i Zakat (The Significance of Zakat) 
29. Hidayat (Directives to The Workers of the Jamaat-i Islami)

30. Hindustan men Muslim Aqalliyat ka Mustaqbil (The Future of the Muslim Minority in India)

31. Human Rights in Islam

32. Huquq al-zawjayn (The Right and Obligations of Spouses)

33. 'Id-i Qurban (The Festival of Sacrifice)

34. Insan ka Ma'ashi Mas'alah awr us ka Islami Hall (Economic Problem of Man and its Islamic Solution)

35. Insan ke Bunyadi Huquq (Fundamental Rights of Man)

36. Ithbat-i Qurbani ba-ayat-i Qur'an (A Qur'anic Vindication of Animal Sacrifice on the Occasion of the Festival of Sacrifice)

37. Islam 'Asr-i Hadir men (Islam Today)

38. Islam awr 'Adl-i Ijtima'i (Islam and Social Justice)

39. Islam awr Jadid Ma'ashl Nazariyat (Islam and Modern Economic Ideology)

40. Islam awr Jahiliyat (Islam and Ignorance)

41. Islam awr Khandant Mansubahbandi (Islam and Family Planning)

42. Islam awr Dabt-i Wiladat (Birth Control; ts social, political, economic, moral and religious aspects)

43. Islam ka Akhlaqi Nuqta-i Nazar (Ethical Viewpoint of Islam)

44. Islam ka Nazariya-i Siyasi (Political Theory of Islam)

45. Islam ka Nizam-i Hayat (Islamic Way of Life)

46. Islam ka Sarchashma- 'i Quwwat (The Mainspring of Islam)

47. Islami Dastur kl Bunyaden (Fundamentals of the Islamic Constitution)

48. Islami Dastur kl Tadwin (First Principles of Islamic State)

49. Islami Hukumat kis Tarah Qa'im hotl hay (The Process of Islamic Revolution)

50. Islami Hukumat men Dhimmiyon ke Huquq (Rights of Non-Muslim in an Islamic State)

51. Islami Ibadat Par ek Tahqiqi Nazar (An Analytical Study of Worship in Islam)

52. Islami Ma'ashiyat ke Usul (The Principles of Islamic Economics)]

53. Islami Nizam-I awr Maghribi Ladini Jamhuriyyat (Islam and the Western Secular Democracy) 
54. Islami Nizam-I Ta'lim (Islamic System of Education)

55. Islami Nizam-I Ta'lim awr Pakistan men us ke Nifadh ki 'Amali Tadabbir (Islamic System of Education and its Introduction in Pakistan)

56. Islami Nizam-I Zindagi awr us ke Bunyadi Tasawwurat (Islamic Way of Life and its Fundamental Concepts)

57. Islami Qanun (Islamic Law)

58. Islami Qanun awr Pakistan men us ke Nifadh ki 'amali Tadabbir (Islamic Law and its Introduction in Pakistan)

59. Islami Riyasat (Islamic State)

60. Islami Tahdhib awr us ke Usul-o Mabadi (The Foundations of IslamicCulture)

61. Islamic Law and Constitution

62. Ittihad-i 'Alam-i Islami (Unity of the Muslim World)

63. Jamaat-i Islami ke 29 Sal (Twenty-nine Years of Jamaat-e-Islami; in the Criterion)

64. Jamaat-i Islami kl Da'wat (The Message of Jamaat-e-Islami; A Contribution Towards Islamic Constitution Making)

65. Jamaat-i Islami kl Intikhabi Jidd-o Jahd, us ke Mawasid, awr Tariq-i Kar (Jamaat-i Islami's election efforts, its aims and its course of action)

66. Jamaat-i Islaml, us ka Maqsad, Tarikh awr Laiha- ' $i$ 'Amal (The Jamaat-i Islam, its aim, history and programme)

67. al-Jihad fi al-Islam (Jihad in Islam)

68. Jihad fi Sabil Allah (The Concept of Jihad in the Way of God)

69. Khatm-i Nubuwat (The Finality of the Prophethood)

70. Khilafat-o-Mulukiyat (Caliphate and Monarchy)

71. Khutba-i Taqsim-i Isnad (Convocation address)

72. Khutbat (Fundamentals of Islam)

73. Khutbat-i Haram (Lectures in the Haram)

74. Kitab al-Sawm (The Book of Fasting)

75. Libas ka Mas'alah (The Question of Dress)

76. Ma'ashiyat-i Islam (Islamic Economies) 
Ibrahim - Reformasi Pendidikan Hukum .....

77. Makatib-i Sayyid Abul A'la al-Mawdudi (Letters of Sayyid Abul A'la alMawdudi)

78. Makatib-i-Zindan (Letter from Prison)

79. Makhlut Intikhab (Joint Electorate-An Objective Evaluation)

80. Makhlut Intikhab kiyawn nahin?(Joint Electorate)

81. Mas'ala- 'i Jabr-o Qadr (The Problem of Free-Will and Predestination)

82. Mas'ala-i Khilafat (The Question of Caliphate)

83. Mas 'ala-i Milkiyat-i Zaniln (The Problem of Land-Ownership)

84. Mas'ala-i Qawmiyat (The Problem of Nationalism)

85. Mas'ala-i Qurbani; Shar'i 'Aqli Nuqta- 'i Nazar se (Animal Sacrifice on 'Id alAdha; in the light of Revelation and Reason)

86. Mashriql Pakistan ke Halat-o Masa'il ka Ja'izah awr Islah kl Tadabir (East Pakistan Problems; Their Causes and Solution)

87. Mawlana Mawdudi ke interview (Interview of Mawlana Mawdudi)

88. Mawlana Mawdudi kl Taqarir (Speeches of Mawlana Mawdudi)

89. Mawlana Sayyid Abul A'la al-Mawdudi ka Tahqiqatl 'Adalat men Dusra Bayan (Sayyid Abul A'la al-Mawdudi's second statement before the Judicial Enquiry Committee)

90. Mawlana Sayyid Abul A'la al-Mawdudi ka Tahqiqatl 'Adalat men Tisra Bayan (Mawlana Sayyid Abul A'la al-Mawdudi's third statement before the Judicial Enquiry Committee)

91. Mi'raj ki rat (The Night of Mi'raj)

92. Munir riport par Jmaat-i Islami ka Tabsirah (An Analysis of the Munir Report; A Critical Study of The Punjab Disturbances Enquiry Report)

93. Murtadd kl Saza Islami Qanun men (The Punishmnet of Apostasy in Islamic Law)

94. Musalman awr Mawjudah Siyasl Kashmakash (Muslims and the Present Political Crisis)

95. Musalmanon ka madi-o hal awr Mustaqbil ke liye Laiha-i 'amal (The Past and Present of The Muslims, and a Programme for the Future) 
96. Muslim Muslim Khawatin se Islam ke Mutalabat (The Demands of Islam from Muslim Women)

97. Muslims and the Christian World; Factors Responsible for Discord and Tension

98. Mutalaba-i Nizam-i Islaml (Demand of the Islamic System)

99. Nashri Taqriren (Radio Talks)

100.Naya Nizam Ta'lim (The New system of education)

101.Nishan-i Rah (Milestones)

102.Nubuwat-i Muhammadi ka 'Aqli Thubut (The Prophet of Islam)

103.Pardah (Purdah and the Status of Women in Islam)

104.Political Thought in Early Islam; in A History of Muslim Philosophy

105.Qadiyant Mas'alah (The Qadiani Problem)

106.Qur'an awr Payghambar (Qur'an and the Prophet)

107.Qur'an Fahmi ke Bunyadi Usul (The Basic Principles of Understanding the Qur'an)

108.Qur'an kl Char Bunyadi Istilahen; ilah, Rabb, 'Ibadat, Din (Four Basic Concepts of the Qur'an: ilah, rabb, 'ibadat, din)

109.Qur'an kl Ma'ashi Ta'limat (Economic Teachings of the Qur'an)

110.Rasail-o Masail (Queries and Responses)

111.Risala-i Diniyat (Toward Understanding Islam)

112.Salajiqah (The Seljuqs)

113.Salamatl ka Rastah (The Road to Peace and Salvation)

114.Samarna men Yunani Mazalim (Greek atrocities in Smyrna)

115.Saniha-i Masjid-i Aqsa (The Masjid Aqsa Tragedy)

116.Sarmayadari awr Ishtirakiyat (Capitalism and Communism)

117.Sarwar-i 'Alam (The Birth of The Prophet and the Leader of the World)

118.Shahadat-i Haqq (Evidency of Truth)

119.Sirat-i Khatm al-Rusul (Biography of the Last Prophet)

120.Sirat-i Pak (The Sirah of The Prophet)

121.Sirat ka Paygham (The Message of the Prophet's Sirah)

122.Sud (Interest)

123.Sunnat kl Abul A'la al-Maududiini Haythiyat (The Status of the Sunnah in Islam) 
124.Tafhim al-Qur'an ${ }^{41}$ (The Meaning of The Qur'an)

125.Tafhimat (Elucidations)

126.Tahrik-i Azadi-i Hind awr Musalman (Freedom Movement in India and the Muslims)

127.Tahrik-i Islami; Kamyabi kl Shara'il (The Islamic Movement; prerequisites of success)

128.Tahrik-i Islami ka Abul A'la al-Maududiindah Laiha-i 'amal (The Future Strategy of the Islamic Movement)

129.Tahrik-i Islami kl Akhlaqi Bunyaden (The Moral Foundations of the Islamic Movement)

130.Tahrik-i Jamhuriyat, us ke Asbab awr us ka Maqsad (The Movement for the Restoration of Democracy)

131.Tajdid-o Ihya'-i Din (A Short History of the Revivalist Movement in Islam)

132.Ta'limat (On Education)

133.Tanqihat; Islam awr Maghribi Tahdhib ka Tasadum awr us ke Paydah-shudah masa'il par Mukhtasar Tabsire (Explications; the Conflict between the Islamic and Western Culture)

134.Tarjuma'i Qur'an-i Majid Ma' Mukhtasar Hawashl (Translation of the Glorious Qur'an with brief notes)

135.Tarjuman al-Qur'an (Monthly Magazine in Urdu edited by Mawlana Mawdudi)

136.Turki men 'Isaiyyon kl Halat (The Condition of Christians in Turkey)

137.Tawhid-o Risalat awr Zindagi Ba'd Mawt ka 'Aqli Thubut (Vitals of Faith)

138.Zindagi Ba'd-i Mawt (Life after Death)

Selain karya-karya Maududi di atas, banyak para penulis di masanya yang meneliti tentang pemikiran dan ide brilian yang dikeluarkannya.Ide dan kejeniusan intelektualnya mulai dikaji dan dikembangkan kembali oleh para penulis dan pengarang serta peneliti kontemporer sekarang di berbagai belahan dunia, termasuk para peneliti Barat maupun di dunia Timur.

\footnotetext{
${ }^{41}$ Buku karangannya Tafhim al-Qur'an adalah sebuah karya beliau yang diselesaikan dalam waktu 30 tahun. Ciri utama buku ini adalah dalam menyampaikan arti dan pesan dalam bahasa dan gaya yang menyentuh hati dan pikiran orang, serta menunjukkan relevansi al-Qur'an dengan masalah-masalah yang mereka hadapi setiap hari, baik sebagai individu maupun dalam masyarakat. Lihat Mukti Ali, Alam Pikiran Islam Modern Di India dan Pakistan, (Bandung: Mizan, 1992), hlm. 242
} 


\section{Bentuk-bentuk Reformasi Pendidikan Hukum}

Reformasi pertama yang dicetuskan Maududi sebagai langkah awal dalam upaya aplikasi pendidikan hukum ialah memutuskan pengetahuan bahasa Arab sebagai prasyarat untuk memasuki akademi hukum. ${ }^{42}$ Langkah ini diambilnya, karena untuk memberikan pemahaman kepada masyarakat luas tentang masalah akidah, akhlak, ibadah dan sebagainya. Mereka harus mengetahui seluk beluk bahasa Arab untuk kegunaan menangkap atau memahami firman Tuhan yang memang diturunkan melalui bahasa Arab. Bahasa Arab penting dipelajari sedini mungkin karena ia merupakan bahasa pengantar di dunia Islam sekaligus sebagai bahasa beribadat kepada Sang Khaliq.

Bahasa Arab menurut Maududi, harus dijadikan sebagai bahasa dunia Islam, karena suatu wawasan yang mendalam atas ayat-ayat al-Qur'an atau hukum Islam hanya dapat dimungkinkan jika menguasai bahasa pengantar dari al-Qur'an itu sendiri. Al-Qur'an sebagai bahasa agama juga harus dijadikan sebagai bahasa pengkajian ilmu pengetahuan (scientific) dan hukum (law). Penggunaan bahasa Arab, khususnya di kalangan siswa/mahasiswa Akademi harus dijadikan sebagai pedoman (rujukan) semua keilmuan dan keputusan hukum yang akan diambil dalam sebuah kepastian hukum.

Ide Maududi tentang pentingnya penekanan bahasa Arab sebagai pra-syarat bagi mahasiswa yang akan memasuki akademi hukum, sangat didukung oleh Muhammad alGhazali (guru dari Yusuf al-Qardhawy). ${ }^{43}$ Al-Ghazali menganjurkan agar lembagalembaga pendidikan bagi para anak sekolah memasukkan kurikulum bahasa Arab sebagai mata pelajaran wajib yang diajarkan di setiap jenjang. Dengan mempelajari bahasa Arab, diharapkan akan berdampak positif bagi pemahaman dan penemuan makna-makna dan kandungan ayat al-Qur'an yang sampai sekarang masih butuh interpretasi-interpretasi yang dalam. ${ }^{44}$ Beribu-ribu rahasia yang tersirat masih banyak yang belum ditemukan di dalam al-Qur'an. Jika umat Islam tidak dididik untuk mengasah dan mempelajari bahasa Arab, maka dikhawatirkan khazanah ilmu yang ada di dalamnya justru dikuasai oleh orang-orang di luar Islam yang mulai menjejaki ilmu-

\footnotetext{
${ }^{42}$ Abul A'la al-Maududi, The Islamic Law..., op.cit., hlm. 130

${ }^{43}$ Muhammad al-Ghazali, Kayfa Nata'amal ma'al-Qur'an, (Mesir: al-Ma'had al-Alami li al-Fikr al-Islami, 1991), hlm. 240

${ }^{44}$ Ibid.
} 
Ibrahim - Reformasi Pendidikan Hukum .....

ilmu dan kandungan yang ada di dalamnya, sebagaimana para orientalis juga berkecimpung mendalaminya.

Gebrakan Maududi untuk mewajibkan mengikuti pendalaman materi bahasa Arab selama setahun sebelum berkecimpung di dalam akademi hukum di Pakistan, pantas diperhitungkan. Idenya ini paling tidak akan membuat sebuah gebrakan bagi para siswa/mahaiswa yang akan memasuki akademi hukum merasa tertantang dan tidak sebatas kemauan belaka. Dengan tantangan yang demikian, mereka paling tidak berusaha mempersiapkan diri dan siap bertempur dalam mengarungi dan meniti seluk beluk hukum serta interpretasi-interpretasinya lebih mendalam ketika duduk di jenjang akademi.

Langkah kedua yang ia ajukan, sejalan dengan pengajaran bahasa Arab adalah mengkaji al-Qur'an dan hadis sebelum mulai pendidikan mereka di bidang hukum. ${ }^{45}$ Langkah ini sejalan dengan penerapan pengetahuan bahasa Arab yang kajiannya samasama bersumber dari bahasa Arab.

Dalam mengkaji al-Qur'an dan hadis, harus benar-benar diarahkan kepada penelusuran ayat dan makna hadis yang sesuai dengan penafsiran kontemporer. Sebelum memasuki materi hukum yang berisikan fiqh (mu'amalah), para mahasiswa akademi hukum harus mengedepankan al-Qur'an daripada pemikiran fiqh (mazhab) yang telah membentuk opini intelektualnya sebelumnya. Kesalahan selama ini adalah mengenalkan hukum-hukum fiqh yang diambil dari salah satu mazhab, sehingga anak merasa satu-satunya jalan yang condong kepada aktivitas yang sesuai dengan syariat Islam, semata-mata hanya diwakili oleh pemikiran mazhab yang telah lama ditransfer oleh orang tua mereka jauh-jauh sebelum memasuki lembaga pendidikan (sekolah).

Mempelajari materi-materi serta pendalaman makna al-Qur'an tidak akan pernah berakhir sesuai dengan derasnya perkembangan wacana dunia serta hegemoni peradaban yang semakin menunjukkan ketidakjelasan. Seiring dengan itu, diskusidiskusi ilmiah tentang penuntasan permasalahan-permasalahan hidup mutlak dibutuhkan dalam menyahuti problema hidup yang semakin menantang.

Seseorang yang telah lulus dalam ujian atau tes bahasa Arab di akademi, selanjutnya akan mengikuti perkuliahan hukum, di mana menurut Maududi, para

\footnotetext{
${ }^{45}$ Abul A'la al-Maududi, The Islamic Law..., op.cit.,hlm. 131
} 
mahasiswa telah siap dengan segala kondisinya untuk mendalami ayat-ayat al-Qur'an yang berhubungan dengan hukum. Baik ditinjau dari kajian fiqh, ushul fiqh, moral, qiyas, ijma' maupun berbagai fenomena dan tinjauan hukum lainnya. Semua ini saling berkait dan tak bisa dipisahkan.

Reformasi ketiga Maududi dalam rangka reformasi pendidikan hukum adalah menekankan kurikulum akademi hukum kepada 3 (tiga) mata kuliah utama yaitu:1. Dasar-dasar yurisprudensi Islam, 2. Sejarah yurisprudensi Islam, dan 3. Fiqh (kajian netral atas semua mazhab fiqh utama). ${ }^{46}$

Ketiga mata kuliah ini menurut Maududi, adalah kunci utama yang akan dapat menghantarkan para mahasiswa akademi hukum benar-benar memahami hukum-hukum fiqh serta hukum-hukum semua perbuatan dan aktivitas manusia. Dasar-dasar atau prinsip-prinsip hukum Islam penting untuk diketahui para mahasiswa karena ia merupakan landasan paling menentukan dalam segenap aktivitas dan cakrawala manusia. Jika prinsip-prinsip tersebut tidak dipahami secara akurat, tentunya mereka tidak akan dapat menerapkan hukum-hukum ini kepada masalah-masalah baru yang selalu muncul setiap hari yang terus menerus menciptakan situasi-situasi terbaru.

Untuk mengatasi permasalahan-permasalahan yang baru muncul, maka sejarah fiqh lah yang harus dikaji ulang kembali untuk mengetahui keputusan hukum yang akan diambil di kemudian hari. Tanpa mengetahui sejarah, maka seseorang akan mengalami rintangan dan kesulitan yang cukup melelahkan dalam mengambil kebijakan (keputusan) hukum. Sejalan dengan itu, analogi juga terasa mandeg dan menerawang, tak tahu dari mana akan memulai sebuah gebrakan yang sesegera mungkin dilaksanakan.

Sejarah hukum dunia Islam membuktikan bahwa pemerintahan Islam telah dilanda kekacauan hukum. Selama satu abad penuh, umat tidak memiliki konstitusi yang dapat diandalkan sehingga semua mahkamah negara dapat berpegang kepadanya dan mengeluarkan suatu keputusan sesuai dengan asas-asas yang dikeluarkannya. Oleh sebab itu, dengan mengetahui sejarah, paling tidak arah dan tujuan ditegakkannya hukum dapat tersosialisasi secara baik. Justru sebaliknya, bila tidak mengenal sejarah

${ }^{46}$ Ibid., hlm. 132 
masa lalu, maka produk hukum yang akan dikeluarkan akan terlihat kaku dan kurang menyentuh kepuasan lapisan masyarakat tertindas.

Mata kuliah ketiga yang kelak dapat menghantarkan kesuksesan bagi seorang penegak hukum adalah mempelajari fiqh secara mendalam dan penuh keseriusan (ketelitian). Mazhab-mazhab fiqh yang berkembang, tidak boleh diterima begitu saja, dalam arti taklid buta, tanpa mengetahui landasan yang mendasarinya. Selanjutnya menurut Maududi, semua mazhab-mazhab fiqh yang beredar di semua lapisan masyarakat Islam tidak boleh serta merta dilegitimasi dan diberikan angin segar untuk mengembangkan pemahamannya kepada masyarakat awam. Semua mazhab fiqh yang ada, harus dipandang secara netral tanpa ada yang diidolakan sebagai rujukan utama dalam pelaksanaan ibadah sehari-hari.

Langkah keempat (reformasi keempat) adalah bersama-sama dengan reformasi kurikulum pendidikan hukum, diikuti pula oleh penataran moral dan pembinaan akhlak mahasiswa. $^{47}$

Penataran moral sangat penting dilakukan bagi segenap para siswa di akademi hukum, karena dalam realitas yang ada di masa menggelindingnya proses pendidikan, ketika masa kehidupan Maududi, banyak di kalangan guru akademi yang sama sekali tidak mementingkan aspek afektif (perilaku moral/akhlak) pendidikan, mereka umumnya hanya mengandalkan aspek kognitif (keilmuan) belaka sehingga wajar saja kalau siswa atau mahasiswa di akademi tersebut hanya belajar hukum sebatas teori tanpa mempunyai niat dan antusias tinggi untuk mengaplikasikan ilmunya secara nyata dan berlandaskan hukum yang dipelajarinya.

Hukum-hukum yang dipelajari para mahasiswa di akademi hukum, biasanya harus berpatokan kepada al-Qur'an. Berbagai gejolak permasalahan yang membutuhkan penyelesaian hukum tentunya juga dipengaruhi oleh alam, karena alam adalah tempat tinggal dan kehidupan bagi manusia. Barang siapa yang merusak alam, maka bencana akan menimpa manusia. Sebaliknya manusia yang menjaga alam dengan seutuhnya, pasti akan terhindar dari mara bahaya.

Fazlur Rahman memandang bahwa ajaran dasar al-Qur'an tentang alam mencakup tiga hal yaitu:

\footnotetext{
${ }^{47}$ Ibid.,hlm. 133
} 
1. bahwa ia merupakan sebuah kosmos

2. bahwa ia merupakan suatu tatanan yang berkembang yang dinamis

3. bahwa ia bukanlah suatu permainan yang sia-sia, tetapi harus ditanggapi secara serius; manusia harus mempelajari hukum-hukumnya, yang merupakan bagian dan perilaku Tuhan, dan menjadikannya sebagai panggung dari aktivitas manusia yang punya tujuan. ${ }^{48}$

Oleh sebab itu menurut Rahman, alam semesta bukanlah tempat kesenangan yang telah "siap pakai" untuk manusia, sehingga mereka tidak mengalami kesulitan. Untuk itu Allah memberikan akal pikiran dan menyerahkan amanat kepada manusia untuk mengelola alam semesta. Menurutnya, hakikat amanat itu adalah menemukan dan menguasai hukum-hukum Tuhan dalam alam semesta dan kemudian menggunakannya di bawah naungan inisiatif moral manusia dalam rangka menciptakan tata dunia yang baik. Aktivitas manusia menjalankan amanat inilah yang merupakan tujuan penciptaan manusia di bawah bimbingan etika dan moral al-Qur'an.

Dalam kesempatan lain, Rahman juga mengungkapkan bahwa tujuan al-Qur'an dalam tatanan sosial adalah untuk menciptakan suatu sistem kemasyarakatan yang etis dan egalitarian (sama). ${ }^{49}$ Oleh sebab itu Rahman memandang hukum Islam bersifat dinamis dan harus dikembangkan sesuai dengan perkembangan zaman.

Pemikiran Rahman yang cukup dinamis, tampaknya memiliki akar pemikiran yang searah dengan Maududi, karena dalam pandangan Maududi, alam itu juga tidak terlepas dari realitas hukum yang akan dijalankan. Hukum-hukum alam merupakan bagian dari perilaku Tuhan yang harus dijawab dan dilestarikan. Oleh sebab itu, bagi para guru atau pendidik di Akademi-Akademi Hukum harus dapat menerapkan pendidikan yang disejajarkan dengan kajian-kajian hukum alam, selanjutnya diaplikasikan ke dalam berbagai metode pengajaran hukum dengan cara mengorkestra berbagai taktik dan pendekatan yang kelak dapat merubah akhlak dan moralitas mereka dalam menerapkan hukum secara murni tanpa peduli gangguan-gangguan yang sifatnya negatif.

\footnotetext{
${ }^{48}$ Fazlur Rahman, "The Qur'anic Concept of God, the Universe and Man", terjemahan T.A. Amal, Metode dan Alternatif Neo Modernisme Islam, (Bandung: Mizan, 1987), hlm. 75

${ }^{49}$ Fazlur Rahman, Major Temes of The Qur'an, terj. Anas Mahyuddin, (Bandung: Pustaka, 1983), hlm. 55
} 


\section{Simpulan}

Reformasi pendidikan hukum yang dilakukan Maududi dapat dilihat pada beberapa langkah, yaitu:

1. Menguasai bahasa Arab sebagai pra-syarat untuk memasuki akademi hukum;

2. Mengkaji al-Qur'an dan hadis sebelum mulai pendidikan mereka di bidang hukum;

3. Menekankan kurikulum akademi hukum kepada 3 (tiga) mata kuliah utama yaitu:
a. Dasar-dasar yurisprudensi Islam,
b. Sejarah yurisprudensi Islam, dan
c. Fiqh (kajian netral atas semua mazhab fiqh utama); dan

4. Bersama-sama dengan reformasi kurikulum pendidikan hukum, diikuti pula oleh penataran moral dan pembinaan akhlak mahasiswa.

\section{E. Daftar Pustaka}

Abul A'la al-Maududi, The Islamic Law and Constitution, Lahore: Islamic Publications Ltd, 1977, Cet. Ke-6

Amin Rais, "Kata Pengantar," dalam Khilafah wa al-Mulk, terj. Muhammad al-Baqir, Bandung: Mizan, 1996

Charles J. Adams, "Maududi dan Negara Islam,"dalam John L. Esposito (Ed.), Dinamika Kebangunan Islam, Terjemahan Bakri Siregar dari buku aslinya "Voices of Resurqen Islam," Jakarta: Rajawali, 1987, Cet. Ke-1

Chaudhri 'Abdur Rahman 'Abd, Mufakkir-i Islam; Sayyid Abul A'laal-Maududi, Lahore: Islamic Publications, 1971

Erwin I. J. Rosenthal, Islam in The Modern National State, Cambridge: University Press, 1965

Fazlur Rahman, Major Temes of The Qur'an, Terj. Anas Mahyuddin, Bandung: Pustaka, 1983

Fazlur Rahman, The Qur'anic Concept of God, the Universe and Man, Terjemahan T.A. Amal, Metode dan Alternatif Neo Modernisme Islam, Bandung: Mizan, 1987

John L. Esposito, The IslamicThreat; Myth or Reality, Bandung: Mizan, 1994

John L. Esposito, The Oxford Encyclopedia of The Modern Islamic World, Volume 3, New York: Oxford University Press, 1995

Khurshid Ahmad \& Zafar Ishaq Ansari, "Mawlana Sayyid Abul A'la Mawdudi: an Introduction to His Vision of Islam and Islamic Law Revival,"dalam Khurshid 
Ahmad \& Zafar Ishaq Ansari (Ed.), "Islamic Perspectives: Studies in Honour of Mawlana Sayyid Abul A'la al-Mawdudi", Leicester: Islamic Foundation, 1980

Khurshid Ahmad dan Zafar Ishaq Anshari, Islamic Perpectives: Studies in Honour of Mawlana Sayyid Abu al-A 'la Maududi, Leicerter: Islamic Foundation, 1980

Maryam Jamilah, Biografi Abul A'la al-Maududi, terj. Dedi Djamaludin Malik, Bandung: Risalah, 1984

Maryam Jamilah, Biografi Abul A'la Maududi, terjemahan Dedy Djamaluddin Malik dari buku aslinya "Who is Maudoodi", Bandung: Risalah, 1984

Muhammad al-Ghazali, Kayfa Nata'amal ma'al-Qur'an, Mesir: al-Ma'had al-Alami li al-Fikr al-Islami, 1991

Mukti Ali, Alam Pikiran Islam Modern Di India dan Pakistan, Bandung: Mizan, 1992

Munawir Sadzali, Islam dan Tata Negara: Ajaran, Sejarah dan Pemikiran, Jakarta: UIPress, 1990

Sayyid Asad Gilana, Maududi; Thought and Movement, Lahore: Islamic Publications, 1984

Sayyid Vali Reza Nasr, Maududi dan Jama'at-i Islami; Asal-Usul, Teori dan Praktik Kebangkitan Islam, dalam Pioneers of Islamic Revival, terj. Ilyas Hasan, Bandung: Mizan, 1995 
